\title{
COMMUNITY HOME-BASED CARE PROGRAMME: A MARGINALISED KEY COMMUNITY RESOURCE
}

\section{Lulama Qalinge}

\section{INTRODUCTION}

The escalating pandemic of HIV and AIDS has challenged the operation of many social institutions globally, regionally and locally, with the health sector bearing the brunt of the scourge. AIDS-related illnesses have killed more than 25 million people globally since the disease was first recognised in 1981, making it the most destructive epidemic in recorded history. Despite recent improved access to antiretroviral treatment and care in many regions of the world, the AIDS epidemic claimed 3.1 million lives in 2005, of which 750000 were children (UNAIDS, 2005:3). The HIV and AIDS pandemic has had a grave impact on Africa, with more than $70 \%$ of the people globally living with HIV and AIDS residing on this continent (UNAIDS, 2005:2).

South Africa is one of the countries in the world most seriously affected by HIV and AIDS. In 2008 an estimated 5.2 million people in South Africa were living with HIV and AIDS. This was more than in any other country in the world (UNAIDS, 2008:8). It is further estimated that in 2008 over 250000 South Africans died of AIDS-related illnesses. The national prevalence is reported to be about $11 \%$, with certain age groups being particularly widely affected. Almost one in three women aged 25-29 years and over a quarter of all men aged 30-34 years are living with HIV (Statistics South Africa, 2009:6). This placed intense pressure on the country's health services and the government has sought the involvement of communities in helping share the burden through encouraging the establishment of community home-based care (CHBC) programmes.

CHBC programmes are normally run and maintained by volunteer caregivers attached to nongovernmental organisations (NGOs), community-based organisations (CBOs) and faith-based organizations (FBOs). The importance and relevance of community home-based care to complement the formal health services have therefore been increasingly recognised, as the latter have not been able to face the challenge alone (NACP 30, 1996:30-31). CHBC programmes are based on the philosophy that all communities are capable of offering services, support and care - as opposed to institutional care - to families that are directly affected by the pandemic. It is further believed that the family home environment is the most appropriate place for the care and support of terminally ill patients. Dant and Gully (1994:72) confirm that removing people living with HIV and AIDS, or any other terminally ill person, from their homes and communities at whatever stage of the illness can facilitate denial, stigma and discrimination. It is also believed that caring for people in their homes and communities makes HIV and AIDS a social and community issue rather than a health problem that affects only an individual and his/her family.

The community home-based care approach should not be viewed as an attempt to shift the burden and responsibility of the government to families in communities, but as a means to ensure that families and community at large take responsibility for the care of infected and affected members at community level. But it remains the government's responsibility to see to it that community home-based caregivers, who are mostly volunteers, are recognised and acknowledged for the services they render in communities. This is especially important 
considering the fact that these caregivers are normally people who are unemployed and not sufficiently literate to secure well-paying jobs.

Against this background, and because of the impression that this community resource including those responsible for rendering the service - is often marginalised to the detriment of those dependent on it, a need was identified to investigate the challenges faced by the community home-based caregivers. The rationale for the research was to create awareness of the conditions under which caregivers operate, with a view to suggesting ways to improve this valuable service and making care giving a productive undertaking.

\section{AIM OF THE STUDY}

The main aim of the study was to assess and explore the experiences of, and the challenges facing, the volunteer caregivers in the rural North West province of South Africa. The focus was on the types of challenges they face as caregivers, the capacities of the caregivers, the psychosocial support available to them, and the need for training.

\section{METHODOLOGY}

The qualitative method was used in the study as qualitative studies are concerned primarily with process rather than outcome or product, and are also more interested in meaning, i.e. how people make sense of their lives and experiences, and the way that they structure their world. The focus was on exploring, describing and explaining people's experiences, behaviours and interactions within their social context (Fossey, Harvey, McDermott \& Davidson, 2002:717). Donalek and Soldwisch (2004:356) indicate that the qualitative researcher seeks to gain indepth understanding of the phenomenon under study from the participants' point of view, because the participants are experts in their experiential worlds and are able to articulate and describe their experiences and feelings until the researcher has gained a fuller understanding of the phenomenon or part of the phenomenon.

During the study caregivers were interviewed in focus groups in the environments where they performed their care-giving duties. The focus group interview is a method of data collection where the researcher interviews a number of respondents in a group for them to answer in discussion form, while the researcher records all the answers and comments, and observes all the emotions arising from the discussion. This method allows for flexibility, because the interviewer has a chance to follow up leads, probe and ask questions for clarification, when necessary (Fossey et al., 2002:727). Non-probability sampling was used to choose the respondents from a population of community caregivers in the North West province and the sample size was determined by the saturation of information obtained. In all 20 groups, each consisting of 5-7 caregivers, were interviewed throughout the province.

\section{DEFINING COMMUNITY HOME-BASED CARE (CBHC)}

Because of the escalating HIV and AIDS pandemic, there has been a dramatic increase in the number of clients or patients requiring care and support. With rising costs of care coupled with the high cost of medical services, the health care centres found themselves unable to cope with the demand. Consequently, it has become necessary to decentralise care to the community level, thereby transferring the responsibility, the cost and the burden on non-governmental organisations (NGOs), community-based organisations (CBOs), faith-based organizations (FBOs) and family carers. CHBC programmes were therefore established to reduce the economic and human resource pressures which health care systems faced. They were also set up to avoid frequent and long hospital stays which are part of AIDS care. The reality of the 
situation is that many patients who are discharged from hospital in an advanced or terminal stage of the illness do not always have family members to care for them within a home setting. There are various reasons for this, such as family members having to go to work, the absence of an adult in the family, poor living conditions and lack of financial stability (Cameron, Coetzee \& Ngidi, 2009:23). It is in such instances that (CHBC) comes into play.

Muchiru and Frohlich (1999:45) describe CHBC as any form of assistance to a sick person in his/her home. Family members, friends and members of the local community supported by skilled health care workers and social workers usually provide this care and are normally referred to as community home-based caregivers. The care given may include palliative or rehabilitative care, physical, psychosocial, spiritual, and material support. Kelesetse (1998:78) similarly defines CHBC as the care given to the individuals in their own natural environment, which is their home, supported by their families, skilled social welfare officers, medical health practitioners and the community at large to meet their spiritual, material and psychosocial needs, with the client playing a crucial role. With CHBC, people living with HIV and AIDS are integrated into the community, making them socially accepted as human beings rather than merely being perceived as AIDS statistics. This integration enables people to see AIDS as a living disease and helps to conscientise and sensitise them to move towards attitudinal change. As a result, the stigma attached to HIV and AIDS may diminish and the clients may well come to eventually find the community a warm and trusting environment.

Cameron et al. (2009:7) explain community home-based caregivers as those who work in the community and carry out one or more functions related to health care delivery; they usually have no formal professional health care qualifications, but are nevertheless key resources within the community. Care giving for both the caregiver and the client/patient is a process of living with hope, faith and courage, the ultimate goal being to ensure that patients/clients spend their last days with dignity (Ursula, 1991:21), knowing they are loved and feeling part of the family and community.

\section{FINDINGS AND DISCUSSIONS}

From the data obtained during focus group interviews, the following central themes describing the experiences and challenges of caregivers emerged as indicated below.

\section{INADEQUATE GOVERNMENT AND COMMUNITY SUPPORT NETWORKS}

All groups consulted expressed dismay at being neglected and abandoned, whilst having to undertake care giving with very little assistance and support from government, relatives, friends and neighbours. This made them feel alone, unappreciated and overwhelmed. The situation, as they explained it, was exacerbated by the high number of clients per caregiver and lack of caregiving equipment such as surgical gloves, diapers, antiseptics and basic medication, which they had expected to be provided by the government. Lack of community assistance, according to the caregivers, is unfortunate and undesirable, and represents a departure from past practice, when community networks afforded help to its sick people (Mensah, 1994:60). This is particularly unfortunate at a time when the South African government heralded the spirit of volunteerism and ubuntu (humanness). To emphasise this ideology Thabo Mbeki, the then South African President, had declared the year 2002 the National Year of Volunteers and also launched the letsema programme (volunteerism) (Advancing the agenda, 2002).

In support of the above points, Khan and Stegling (2000:18) confirm that most of the time caregivers feel unsupported by their families, relatives and the community at large, while research findings in Zimbabwe on care giving suggested that care programmes are not 
supported by their communities (UNAIDS, 1999:24). The unfortunate dwindling of the black African altruistic spirit with time is a result of black Africans embracing Westernization and the Eurocentric values of individualism, thus abandoning the traditional communal or socialistic style of living that saw people doing work together for the good of all in the society. The concept of helping one another and sharing has always been at the core of African values (Makhubele, 2009:89). It is in this context that the notion of home-based care was envisaged.

\section{INADEQUATE SUPERVISION BY HEALTH CARE PERSONNEL}

Caregivers lamented that they are rarely supervised by health care professionals and they thus felt inadequate, as they often require professionals to guide them in what they have to do. Since most of them have a limited education, they are not always sure whether they are doing the right things or not, hence the relevance and importance to them of continued supervision by health care professionals. Health professionals, on the other hand, feel overwhelmed with the work load as a result of the shortage of staff in clinical areas (Atta \& Fidzani, 1996:8). There was a general feeling amongst participants that clinics or health care centres are by and large understaffed and thus impose a burden on both health care workers and caregivers. The Nurses Association of Botswana (NAB, 2004:21) alluded to a general inadequacy of health personnel in many poor countries as a result of under-staffing. Jacques and Stegling (2001:8) concur that health care providers are failing to supervise community caregivers in their care-taking, whilst Atta and Fidzani (1996:6) indicate that 95\% of the caregivers lacked supervision and support from health workers. It can thus be concluded that lack of professional supervision has a negative impact on the quality of care giving, thus posing a challenge to caregivers at grassroots level. It is therefore ethically unacceptable that this category of health care worker should be allowed to function independently. In the final instance it is the professional health care worker who is responsible for the assessment of the patient and for developing the care plan which the caregivers are involved in implementing. Consequently, the implementation process equally needs supervision, support and training of caregiver so that together they can provide holistic patient care and family support (Cameron et al., 2009:9).

\section{LACK OF PSYCHOLOGICAL SUPPORT}

Care giving to the terminally ill was described by participants as being taxing, overwhelming and psychologically draining. Caregivers' repeatedly echoed lack of psychological support in the form of counselling or debriefing to ease the emotional strain as indicated above. They were of the view that lack of professional psychological support leads to stress, burnout and low morale. They emphasised this as the main reason for the high turnover of persons in care giving.

Debriefing and counselling are expected to help make caregivers come terms with the reality of the situation, instils hope and confidence, and consequently encourages caregivers to seek support and to share with others in order to reduce the psychological and emotional burden on them. As suggested by the NAB (2004), UNAIDS (2000) and Uys and Cameron (2003), it is the role of the government (Department of Health and Social Development) and organisations in the field of care giving to provide professional counsellors to caregivers to alleviate the psychological strains that can lead to feelings of isolation, stress, burnout and low morale amongst them. It is also the role of social workers to encourage caregivers to form support groups, because it is through support groups that caregivers' feelings and experiences are legitimised, and they are provided with a framework for coping (White \& Madara, 1992:19). It is on the basis of this that caregivers expressed their need to be afforded the opportunity to share experiences and gain support from each other through the establishment of support 
groups. Meeting others like them who have experienced a similar problem would, according to them, give a them sense of belonging, thus maximising emotional health. Since most of them are not educated or are illiterate, the involvement of professionals in facilitating support groups seemed the right thing for them. The participants expressed a strong need to see health professionals showing interest in their work and acknowledging the challenges they face in the world of care giving. Support groups are considered a valuable tool in the breakdown of secrecy and isolation, and in fostering an environment of psychological wellbeing (Want \& Williams, 2000:14; Yalom, 1985).

Most groups lamented that though they do the work on a voluntary basis, and are sometimes forced to use their own limited resources, the CHBC programme provides no incentives, rewards or any strategies to motivate the caregivers. Huczynski (1987:251) explains the purpose of an incentive or reward as facilitating positive changes or behaviour that could result in increased productivity. Incentives, according to the participants, should include receiving stipends, bonuses, encouraging words, food packages, regular visits and supervision by health professionals. In other African countries the situation is different. For instance, in Zimbabwe caregivers receive as an incentive a year's pocket-money in a lump sum, whilst in Uganda the Aids Service Organisation (TASO) assists with the education of at least two children of each caregiver (UNAIDS, 1999:23).

\section{IMPACT OF POVERTY ON CARE GIVING}

The study revealed that most caregivers are from disadvantaged families, as $88 \%$ of them had no source of income. Most rely on welfare grants, food parcels and doing menial jobs within the community. Some get involved in doing care work because they feel it is better than staying at home without anything to do. This, according to respondents, moves the focus away from the "house" towards looking at their engagement as part of a community. A study by Mojapelo, Ditirafalo, Tau and Doehlie (2001:20) established that $85 \%$ of the caregivers were not employed and often cited poverty as a stumbling block in the provision of good care. Another study by Khan and Stegling (2000:23) found glaring poverty amongst the caregivers, as evidenced in a lack of the most basic necessities, with the lack of food being the gravest. The final element worth noting is this regard is that irrespective of how little they have, caregivers have an undying commitment to serve their families and communities. This, they indicated, gives them a purpose in life and they hope that the government will someday reward them in one way or another.

Caregivers felt they have social and cultural responsibility to take care of the sick. Mensah (1994:60) indicated that irrespective of poverty, communities especially in Africa have been helping each other in times of sorrow and distress.

\section{LACK OF TRAINING}

As indicated above, the study revealed that most of the caregivers were illiterate or had low levels of education, which calls for continuous in-service training. According to participants, training is offered only on an intermittent basis. They expressed their commitment and willingness to work for the community, but emphasised their lack of writing and language skills. This affirms the need for skills development. Atta and Fidzani (1996:8) confirmed that only $10 \%$ of caregivers receive appropriate training for their task. Because of illiteracy, $11 \%$ of the caregivers they studied found the instructions for the administration of the medicine that they were responsible for too complicated, making care giving a stressful task. Petit (1994:4) 
emphasises the need for, and importance of, periodical training to the caregiver if good results are to be realised.

According to Cameron et al. (2009:10), community caregivers need training in home care, palliative care, infection control, psycho-social support as well as record keeping. Given the high rate of HIV and AIDS, it is imperative for caregivers to receive training in caring for HIVpositive people at home, and in understanding the implications of the HIV status of family members. It is also essential that caregivers be trained in pain management as, according to them, this is usually beyond the scope of what they can manage. This is mostly required when a person in their charge is dying. Losing a patient usually leaves carers with a sense of defeat, and a feeling that they have rendered a poor service or failed to save a patient's life.

\section{CONCLUSION AND RECOMMENDATIONS}

Given the fact that community caregivers are a key community resource in providing assistance and care to many who would otherwise have little access to any form of assistance, there is a critical need to support and acknowledge the work done by them. Caregivers have to deal with matters such as stigmatisation and discrimination, the emotional stress of repeated loss of clients, the physical strain of having to walk long distances to reach their patients or clients, lack of income, lack of adequate training, lack of psychological support and lack of recognition, all of which contribute to feelings of stress and fatigue. This indicates that they are a marginalised and uncared for category of workers, who should in fact be regarded as a key community resource. All this, coupled with the physical and emotional cost of providing care that is unpaid and undervalued, poses a serious challenge to willing community caregivers in rendering their valuable service. While the caregivers' contribution cannot be over-emphasised as a very important community resource, it is apparent that they face many challenges, which in turn makes their contribution lacking in many aspects necessary to make care giving a success and to ensure quality care.

Against the above background and in order to ensure that caregivers are enabled to render an effective service, the following recommendations are made:

- Social workers and professional health care workers should work together to assist community caregivers in their efforts to provide a valuable service to the community. This calls for a structured, formalised, and coordinated working relationship among the various health units within the Department of Health and Social Development and NGOs/CBOs responsible for caregivers. A structured, formalised and coordinated relationship is anticipated to encourage regular supervision, on-going training, care, and recognition of caregivers for the valuable service that they render.

- Legislation should be promulgated to regulate the functioning of community caregivers, if possible by placing them under the auspices of a particular statutory professional body. This will assist in developing standards or guidelines needed to streamline their functioning with a view to protecting clients and caregivers themselves.

- Stipends payable to caregivers to cover transport costs and meals are imperative. This will serve as an incentive to encourage commitment and security.

- Adequate provision of care-giving tools such as disposable diapers, gloves, antiseptics and protective clothing must be provided at regular intervals.

- Social workers as community brokers must be encouraged to provide a link between caregivers and health care professionals to facilitate provision of care giving tools or requirements. 
In conclusion, it should be emphasised that, notwithstanding the fact that most community home-based caregivers do not have formal education, it is necessary to involve them in the decision-making processes of the CHBC programme. Since they are involved in the service at grassroots level, their suggestions may contribute to the quality of care of patients. This may also further improve their image and dignity within the community.

\section{BIBLIOGRAPHY}

ADVANCING THE AGENDA. 2002. Africans urge high level backing for volunteer action. [Online] Available: http://www.unv.org/infobase/unv news.

ATTA, J.K. \& FIDZANI, N.H. 1996. Baseline study for Community Home Based Care Programme for Terminally ill HIV/AIDS patients in Botswana. NACP 31. AIDS STD unit, Gaborone, Botswana.

CAMERON, S., COETZEE, L. \& NGIDI, N. 2009. Legal aspects of palliative care. Hospice Palliative Care Association of South Africa.

DANT, T. \& GULLY, V. 1994. Coordinating care at home. London: Collins.

DONALEK, J.G. \& SOLDWISCH, S. 2004. Demystifying nursing research: an introduction to qualitative research methods. Urologic Nursing, 24(4):354-356.

FOSSEY, E., HARVEY, C., McDERMOTT, F. \& DAVIDSON L. 2002. Understanding and evaluating qualitative research. Australian and New Zealand Journal of Psychiatry, 36:717732.

HUCZYNSKI, A. 1987. Encyclopedia of organizational change methods. Brookfield, VT, U.S: Gower.

JACQUES, G. \& STEGLing, C. 2001. Panacea or perfidy? Paper presented at the $3^{\text {rd }}$ International Conference on Social Work in Health and Mental Health, July 1-5, 2001, Tampere, Finland.

KELESETSE, N.M. 1998. AIDS, home based care and the status of women in Botswana: a case study of Mogoditshane. Gaborone: University of Botswana. (Unpublished dissertation)

KHAN, B. \& STEGLING, C. 2000. An evaluation of the Kweneng district AIDS Home Based Care Programme, Gaborone: SNV, Netherlands Development Organisation.

MAKHUBELE, J.C. 2009. Indeginising life skills education. North West University. (Unpublished dissertation)

MENSAH, M. 1994. Home based care for people with HIV/AIDS: Agomaya, Ghana. Development in Practice, 4(1):58-62.

MOJAPELO, D., DITIRAFALO, T., TAU, M. \& DOEHLIE, E. 2001. Client satisfaction and providers perspectives of home based care in Kweneng District, Botswana. Unpublished Report, Gaborone.

MUCHIRU, S. \& FROHLICH, J. 1999. HIV/AIDS home based care. Gaborone: MacMillan. NATIONAL AIDS CONTROL PROGRAMME (NACP) 30. 1996. Community home based care for people living with AIDS in Botswana. AIDS STD Unit, Gaborone. 
NATIONAL AIDS CONTROL PROGRAMME (NACP) 31. 1996. Baseline study for the community home based care programmes for terminally ill HIV/AIDS patients in Botswana. Gaborone, Botswana.

NURSES ASSOCIATION OF BOTSWANA (NAB). 2004. Caring for the caregivers. Gaborone, Kgotla Designs.

PETIT, P. 1994. Closing the performance gap. Health Action, (8):4.

STATISTICS SOUTH AFRICA. 2009.

UNAIDS. 1999. Comfort and hope. Six case studies on mobilizing family and community care for and by people with HIV/AIDS, June.

UNAIDS. 2005. AIDS epidemic. December 2005.

UNAIDS. 2008. Caring for carers. Managing stress in those who care for people with HIV and AIDS. UNAIDS Case study.

URSULA, S. 1991. Review of community based care programme in Uganda: Kitovu mobile AIDS home care programme in the report of the regional workshop on HIV/AIDS community based care and control, 6-11 October. Entebe: Commonwealth Secretariat. and WHO

UYS, L. \& CAMERON, S. 2003. Home based HIV/AIDS care. Oxford: Oxford University Press.

WANT, C. \& WILLIAMS, P. 2000. Adventures in group work. Dulwich Centre Journal, $1 \& 2: 11-17$.

WHITE, B.J. \& MADARA, E.D. 1992. The self-help sourcebook. American Self-Help Clearinghouse, Denville, New Jersey.

YALOM, I.D. 1985. The theory and practice of group psychotherapy. New York: Basic Books.

Prof Lulama Qalinge, Department of Social Work, University of South Africa, Pretoria, South Africa. 